\title{
Estimation of Nonlinear Parameters of Type 6 Hydrological Method in Flood Routing With the Spotted Hyena Optimizer Algorithm (SHO)
}

Saeid Khalifeh ( $\nabla$ khalifeh.saeid@mail.um.ac.ir)

Ferdowsi University of Mashhad

Kazem Esmaili

Ferdowsi University of Mashhad

S. Reza Khodashenas

Ferdowsi University of Mashhad

Fereshteh Modaresi

Ferdowsi University of Mashhad

\section{Research Article}

Keywords: Non-linear Muskingum model, Sum of Square Error (SSQ), Spotted hyena optimizer Algorithm, Flood routing

Posted Date: June 17th, 2021

DOI: https://doi.org/10.21203/rs.3.rs-619835/v1

License: (c) (i) This work is licensed under a Creative Commons Attribution 4.0 International License. Read Full License 


\author{
1 Estimation of Nonlinear Parameters of Type 6 Hydrological Method in Flood Routing with \\ the spotted hyena optimizer Algorithm (SHO) \\ $4{ }^{a}$ Ph.D. Candidate in Water Science and Engineering, Ferdowsi University of Mashhad, Mashhad, Iran \\ 5 (Corresponding author, Email: khalifeh.saeid@mail.um.ac.ir) \\ 6 bAssociate Professor, Department of Water Engineering, Ferdowsi University of Mashhad, Mashhad, Iran \\ $7 \quad$ 'Professor, Department of Water Engineering, Ferdowsi University of Mashhad, Mashhad, Iran \\ $8{ }^{d}$ Assistant professor, Department of Water Engineering, Ferdowsi University of Mashhad, Mashhad, Iran
}

\title{
9 Abstract
}

10 In this study, The Spotted hyena optimizer Algorithm (SHO) is used to optimize the parameters of the

11 Non-linear type 6 Muskingum model for flood routing. To evaluate the performance of the SHO in the

12 Non-linear Muskingum models, The Wilson River and the Wye River are applied by many researchers for

13 validation. Moreover, in these studies, the Non-linear Muskingum parameters were estimated by the SHO

14 Algorithm. The SSQ and DPO were considered as objective functions between computed and observed

15 data. According to the results of Wilson river flood, the values of these objective functions for the NL3

16 model are 128.781, and $0.92 \mathrm{~m}^{3} / \mathrm{s}$, and for the NL6 model, are 3.20 and 0.027 , respectively. The results of

17 the Wye River flood with the SHO showed that the SSQ and DPO for the NL3 model are 34789.39 and

1890.05 , and for the NL6 model are 30812.07 and 72.35, respectively. The results show that the proposed

19 algorithm can be applied confidently to estimate the parameter optimal values of the nonlinear

20 Muskingum model. Moreover, this algorithm may be applicable to any continuous engineering 21 optimization problems. 
22 Keywords: Non-linear Muskingum model, Sum of Square Error (SSQ), Spotted hyena optimizer

23 Algorithm, Flood routing

\section{1. Introduction}

25 Flood means an increase in the water height of a river, and occupation of the riverbanks which

26 lead to damage to the buildings and public installations and causes human and animal casualties.

27 In some cases, floods can be caused by increasing water height in the lake or the sea, which can

28 have a profound effect on high winds.

29 Flood routing is a mathematical method for forecasting changes in the volume, velocity and

30 flood waveform in the channel as a function of time, which is of great importance in river

31 engineering, river protection, flow modeling in reservoir and weirs. The problem of flood routing

32 can be solved by hydraulic and hydrological methods depending on the conditions and

33 information available from the river (Ahmed et al., 2019). Hydrological routing is the principle

34 of continuity of flow and described the relationship between the outflow and flood storage along

35 the route, and the results are sufficiently accurate for use in the waterworks. In the other

36 methods, the complex hydraulic principles and laws of unsteady flows were used in the open

37 waterways, which are called hydraulic routing (Hamedi et al., 2016).

38 The Muskingum model is one of the hydrological routing methods first developed by McCarthy

39 (McCarthy, 1938). The method introduced by McCarthy was a linear relationship and did not

40 have the ability to model non-linear relationships between the inflow, outflow and flood storage. 
41 However, Gill (2006) developed a Non-linear version of this method. The important point in

42 using a Non-linear Muskingum method is to determine the appropriate values of its parameters,

43 which are usually determined by trial-and-error or using time-consuming numerical methods.

44 Therefore, using optimization methods to determine these parameters is an excellent solution.

45 The Non-linear hydrological model is presented using equations 1 and 2 (Das, 2004):

$\frac{\mathrm{ds}}{\mathrm{dt}}=\mathrm{I}_{\mathrm{t}}-\mathrm{O}_{\mathrm{t}}$

$\mathrm{S}_{\mathrm{t}}=\mathrm{K}\left[\mathrm{XI} \mathrm{t}_{\mathrm{t}}+(1-\mathrm{X}) \mathrm{O}_{\mathrm{t}}\right]$

46 Where $\mathrm{S}_{\mathrm{t}}, \mathrm{O}_{\mathrm{t}}$ and $\mathrm{I}_{\mathrm{t}}$ denote the values of the flood storage, outflow and inflow at time $t$,

47 respectively, $\mathrm{K}$ is the storage duration to reach the river, which provides the flow time via the

48 river, and $\mathrm{X}$ is a weight Coefficient between $(0,0.3)$.

49 The standard method for applying the Muskingum model involves two steps including parameter

50 estimation and flood prediction (Das, 2004).

51 In the first step, the Muskingum parameters are determined using historical input-output data

52 recorded from the river hydrographs. In the second step, the flood is predicted using the

53 Muskingum Routing Equations. A routing plan is suggested, where the relationship between the

54 flood storage and Non-linear weight flow is introduced. In the past studies, five types of Non-

55 linear Muskingum model have been reported (Chow (1959), Gavilan and Hook (1985), Gill

56 (1978), Easa (2013), Haddad et al. (2015)). 
57 In the Muskingum Linear Model by Combining Exponential Parameters with Inflow and 58 Outflow Flood Storage Equation, Nonlinear versions 1 and 2 were obtained in the first and 59 second stages, respectively. Using the weighted storage flow and considering the exponential 60 parameters, the Muskingum version 3 (NL3) model was developed, which was the most widely

61 used model among researchers. The algorithms used in this model can be referred to the Nord 62 algorithm, GOA algorithm, Bat algorithm, SOS algorithm and etc (Ghaleni et al., 2010; Farzin 63 et al., 2018; Khalifeh et al., 2020; ).

64 The NL1 and NL2 storage equations were combined and the fourth Non-linear version of the 65 Muskingum (NL4) model was obtained.

66 Easa (2013) introduced the purpose of developing a Flood Routing Model using the Muskingum 67 method to create a greater degree of freedom. Omid Bozorghad et al. (2015) introduced a Non68 linear Muskingum model that modified the structure of the NL4 storage model as NL5. This 69 model has greater degrees of freedom than the standard NL4 and offers 7 nonlinear Muskingum 70 parameters (Haddad et al., 2015).

71 The NL6 Model was presented to NL5 by adding an improvement coefficient $\gamma$, which takes less 72 than and more than one due to the peak flow rate in the outflow hydrograph (Tabari et al., 2018).

73 According to the mentioned literature, Non-linear 3 was used as the most widely used method 74 and a Non-linear 6 was used as the developed method.

75 In this paper, the method is based on a powerful nature-inspired intelligent technique called 76 spotted hyena optimizer Algorithm (SHO) to optimize the Non-linear model parameters. 
77 The novelty of this paper is that for the first time in the new nonlinear Muskingum model called

78 Model NL6 with 8 variables, the SHO algorithm was used.

79 In the present study, first, the performance of the SHO algorithm compared to other meta-

80 heuristic algorithms such as Genetic Algorithm (GA) and Imperialist Competitive Algorithm

81 (ICA) were investigated in the NL3 model for the Wilson River. Thereafter, based on the SHO

82 algorithm, the calculated parameters from the NL3 and NL6 Muskingum models were compared

83 for the Wilson and Kardeh River.

\section{2. Methods}

\section{2.1. The Non-linear 3 (NL3) Muskingum Model}

86 The Non-linear Muskingum model version 3 is derived from the following equations.

$87 \quad S_{t}=K\left[I_{t} X+O_{t}(1-X)\right]^{m}$

$88 \quad \mathrm{~S}_{\mathrm{t}}=\mathrm{K}\left[\mathrm{I}_{\mathrm{t}}^{\mathrm{m}} \mathrm{X}+\mathrm{O}_{\mathrm{t}}{ }^{\mathrm{m}}(1-\mathrm{X})\right]$

89 Where $\mathrm{I}_{t}, \mathrm{O}_{\mathrm{t}}$ and $\mathrm{S}_{\mathrm{t}}$ are, inflow, outflow and flood storage, respectively. $\mathrm{K}$ is the dimensionless

90 coefficient of storage for the river and It is considered a reasonable value close to the time that

91 the flow passes through the entire river, and $\mathrm{X}$ is a weight coefficient between $(0,0.5)$ (Mohan,

92 1997; Kim et al., 2001; Chu and Chang, 2009).

93 2.1.1. Method of Estimating Flood Routing Parameters Using NL3 Proposed Model

94 Using Equation 5, the outflow is obtained (Karahan et al., 2013):

$95 \quad O_{t}=\left(\frac{1}{1-X}\right)\left(\frac{S_{t}}{K}\right)^{\frac{1}{m}}-\left(\frac{X}{1-X}\right) I_{t}$ 
96 The following equations are derived from the combination of Equations (1) and (3):

$$
\begin{aligned}
\frac{\Delta \mathrm{s}_{\mathrm{t}}}{\Delta \mathrm{t}} & =-\left(\frac{1}{1-\mathrm{X}}\right)\left(\frac{\mathrm{S}_{\mathrm{t}}}{\mathrm{K}}\right)^{\frac{1}{\mathrm{~m}}}+\left(\frac{1}{1-\mathrm{X}}\right) \mathrm{I}_{\mathrm{t}} \\
S_{t+1} & =\Delta S_{t}+S_{t}
\end{aligned}
$$

$97 \mathrm{~S}_{\mathrm{t}+1}$ is the storage at time $\mathrm{t}+1$. Geem (2006) calculated the flood hydrograph using the above

98 equations and employed the following algorithm:

99 Step 1: Suppose the initial value for the K, X, and m parameters

100 Step 2: Computing the flood storage $\left(\mathrm{S}_{\mathrm{t}}\right)$ using equation (3) supposing that the initial outflow is

101 equal to the inflow $\left(\mathrm{O}_{1}=\mathrm{I}_{1}\right)$.

102 Step 3: Computing the ratio of flood storage to the time using equation (6).

103 Step 4: Computing the amount of storage using equation (7).

104 Step 5: Computing the outflow volume using Equation (5).

105 Step 6: Repeat steps1 to 5.

\section{2.2. The Non-linear 6 (NL6) Muskingum Model Procedure}

107 In this study, the modified version of this model is used which be firstly proposed by Tabari et al.

108 (2018), called the Non-linear type 6 model (NL6). The NL6 method was originally proposed by

109 Chow (1959).

$110 \quad S_{\text {in }}=b\left(\frac{I}{a_{1}}\right)^{\frac{m}{n_{1}}}$

$111 S_{\text {out }}=b\left(\frac{O}{a_{2}}\right)^{\frac{m}{n_{2}}}$ 
112 Where $a_{1}$ and $n_{1}$ describe the parameters associated with the characteristics of the river upstream

113 depth-discharge relationship; $\mathrm{a}_{2}$ and $\mathrm{n}_{2}$ reveal the characteristics of the downstream depth -

114 discharge. By substitution of $S_{\text {in }}$ and $S_{\text {out }}$, from Eq. (8) and (9) in $S=\left[X S_{\text {in }}+(1-X) S_{\text {out }}\right]^{\beta}$, the Eq.

115 (10) is produced.

$116 S=K \gamma\left[X\left(C_{1} 1^{\alpha 1}\right)+(1-X)\left(C_{2} O^{\alpha 2}\right)\right]^{\beta} \quad(N L 5)$

$117 \quad(10)$

$118 K=b^{\beta}$

$119 \quad \alpha_{1}=\frac{m}{n_{1}}$

$120 \quad \alpha_{2}=\frac{m}{n_{2}}$

$121 \quad C_{1}=\left(\frac{1}{a_{1}}\right)^{\alpha_{1}}$

$122 \quad C_{2}=\left(\frac{1}{a_{2}}\right)^{\alpha_{2}}$

123 Where $\mathrm{I}$ and $\mathrm{O}$ are the inflow and outflow rate $\left(\mathrm{m}^{3} / \mathrm{s}\right), \mathrm{K}$ is the reserve constant which is greater

124 than $0 . \mathrm{X}$ is the dimensionless weight coefficient between 0 and 0.3 , indicating the relative 125 effects of the input and output flow on the reservation. $\alpha_{1}, \alpha_{2}$ and $\beta$ are the exponential 126 parameters, and $\gamma, \mathrm{C}_{1}$ and $\mathrm{C}_{2}$ are the fixed parameters that are greater than zero. The parameter $\gamma$ 127 is actually the coefficient determining the linearity and nonlinearity of the output hydrograph

128 Its value is less than one for single-point flow hydrographs and more than one for multi-point 129 flow hydrographs. S also indicates the storage volume. 
131 The NL6 model has 8 parameters including $\mathrm{K}, \mathrm{X}, \mathrm{C}_{1}, \mathrm{C}_{2}, \gamma, \alpha_{1}, \alpha_{2}$ and $\beta$ which is more complex

132 and accurate compared to the other Non-linear models. These parameters are obtained using

133 optimization models.

\section{2.2.1. Method of Estimating Flood Routing Parameters Using NL6 Proposed Model}

135 In this article, Tabari et al (2018) method are used to simulate the flood routing model with

136 version NL6. The simulation steps of the flood routing in NL6 method are as follows:

137 Step 1: Suppose the initial value of model parameters $\left(K, X, C_{1}, C_{2}, \alpha_{1}, \alpha_{2}, \beta, \gamma\right)$

138 Step 2: Compute the initial flood storage $\mathrm{S}_{0}$, using equation (16). Permit the initial computed

139 output flow be equal to initial Observed input flow $\left(\hat{\mathrm{O}}_{0}=\mathrm{I}_{0}\right)$ :

$140 \quad 6(1$

$$
S_{0}=K \gamma\left[X\left(C_{1} I^{\alpha 1}\right)+(1-X)\left(C_{2} O_{0}^{\alpha 2}\right)\right]^{\beta} i=0
$$

141 Step 3: Compute the rate of flood storage volume at time interval $\mathrm{t}$ (beginning by $\mathrm{i}=1$ ):

142

$$
\frac{\Delta S_{i}}{\Delta t}=I_{i}\left\{\left[\frac{1}{(1-X) C_{2}}\right]\left(\frac{S_{i}}{K \gamma}\right)^{\frac{1}{\beta}}-\left[\frac{1}{(1-X) C_{2}}\right]\left[\left(C_{1} I^{\alpha 1}\right) X\right]\right\}^{\frac{1}{\alpha 2}}
$$

143 Step 4: Compute the flood storage at time i:

$144 \quad S_{i}=\left(\frac{\Delta S_{i-1}}{\Delta t}\right) \Delta t+S_{i-1}$

145 Step 5: Compute the output flow at time interval i:

146

$$
\partial_{i}=\left\{\left[\frac{1}{(1-X) C_{2}}\right]\left(\frac{S_{i}}{K \gamma}\right)^{\frac{1}{\beta}}-\left[\frac{1}{(1-X) C_{2}}\right]\left[\left(C_{1} I_{i-1}^{\alpha 1}\right) X\right]\right\}^{\frac{1}{\alpha 2}}
$$

147 Consider that $\mathrm{I}_{\mathrm{i}-1}$ rather than $\mathrm{I}_{\mathrm{i}}$ is used in Equation. (19), following the method of Geem (2006).

148 Step 6: 1 unit increasing with $\mathrm{i}$ and repeat steps (3) to (5) until time N. 


\section{3. The Spotted hyena optimizer Algorithm (SHO)}

150 In this article, for the first time, estimating the Non-linear type 3 and 6 is applied by the

151 population-based optimization algorithm and nature-inspired, which is called The Spotted hyena

152 optimizer Algorithm (SHO) (Dhiman and Kumar, 2017). The optimization results demonstrate

153 that the SHO algorithm is very competitive compared to other evolutionary algorithms. The main

154 steps of this algorithm are as follows (Dhiman and Kumar, 2017):

\section{5 (i) Encircling prey}

156 For Encircling prey, the best solution is considered as objective hunting. Search agents or hyenas

157 can identify and improve their position according to this state by identifying. Mathematical

158 modeling of this behavior is shown by Equations (20) and (21):

$159 \quad \stackrel{\mathbf{D}}{\mathrm{D}}_{\mathrm{h}}=\left|\stackrel{\mathrm{m}}{\mathrm{B}}_{\mathrm{p}}(\mathrm{x})-\stackrel{\mathrm{u}}{\mathrm{P}}(\mathrm{x})\right|$

$160 \quad \stackrel{\mathrm{m}}{\mathrm{P}}(\mathrm{x}+1)=\stackrel{\mathrm{m}}{\mathrm{P}}_{\mathrm{p}}(\mathrm{x})-\stackrel{\mathbf{m}}{\mathrm{E}} \cdot \stackrel{\mathrm{L}}{\mathrm{D}}_{\mathrm{h}}$

161 Where $\stackrel{\mathrm{D}}{\mathrm{D}}_{\mathrm{h}}$ displays the distance between the prey and spotted hyena; $\mathrm{X}$ indicates the current

162 iteration, $\stackrel{\mathrm{B}}{\mathrm{B}}$ and $\stackrel{\mathrm{E}}{\mathrm{E}}$ are factor vectors; $\stackrel{\mathrm{m}}{\mathrm{P}}$ is the location vector of prey; $\stackrel{\mathrm{P}}{\mathrm{P}}$ is the location vector

163 of spotted hyena.; || is the absolute amount, and (.) Is Dot product. The factors vectors are

164 estimated as the following equations:

$165 \quad \stackrel{\mathbf{B}}{\mathrm{B}}=2 \cdot \mathrm{rd}_{1}^{\mathbf{u}}$

$166 \stackrel{\text { ut }}{\mathrm{E}}=2 \stackrel{\mathbf{1}}{\mathrm{h} \cdot \mathrm{rd}_{2}}-\stackrel{\mathrm{I}}{\mathrm{h}}$ 
168 Where $\mathrm{h}$ is the factor that reduced linearly from 5 to 0 during iterations (in two stages of

169 identification and colonization) and $\mathrm{rd}_{1}, \mathrm{rd}_{2}$ are stochastic vector in the distance 0 to 1.

170 ii) Hunting

171 The next step of this algorithm is a hunting strategy that forms a set of optimal solutions against

172 the best search agent and position update.

173 The following equations are described in this mechanism:

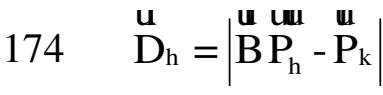

$175 \quad(25)$

$176 \quad \stackrel{\mathrm{m}}{\mathrm{P}}_{\mathrm{k}}=\stackrel{\mathrm{m}}{\mathrm{P}}_{\mathrm{h}}-\stackrel{\mathrm{m}}{\mathrm{E}} \cdot \stackrel{\mathrm{D}}{\mathrm{D}}_{\mathrm{h}}$

$177 \quad \stackrel{\mathbf{C}}{\mathrm{C}}_{\mathrm{h}}=\stackrel{\mathrm{m}}{\mathrm{P}}_{\mathrm{k}}-\stackrel{\mathrm{P}}{\mathrm{P}}_{\mathrm{k}+1}+\ldots+\stackrel{\mathrm{m}}{\mathrm{P}+\mathrm{N}}$

178 Where $\stackrel{\mathrm{P}}{\mathrm{h}}_{\mathrm{h}}$ defines the position of first best spotted hyena, $\stackrel{\mathrm{m}}{\mathrm{P}}$ indicates the position of other

179 spotted hyenas. Here, $N$ indicates the number of spotted hyenas which is computed as follows:

$\mathrm{N}=\operatorname{count}_{\text {nos }}\left(\stackrel{\mathrm{P}}{\mathrm{h}}_{\mathrm{P}}, \mathrm{P}_{\mathrm{h}+1}, \mathrm{P}_{\mathrm{h}+1}, \ldots,\left(\mathrm{P}_{\mathrm{h}}+\stackrel{\mathrm{M}}{\mathrm{M}}\right)\right)$

181 Where $M$ is a stochastic vector in $[0.5,1]$, nos defines the number of solutions and count all

182 candidate solutions, after addition with $M$, which are far similar to the best optimal solution in a

183 given search space, and $\stackrel{\mathbf{C}}{\mathrm{h}}_{\mathrm{h}}$ is a group or cluster of $N$ number of optimal solutions.

\section{4 (iii) Attacking prey (exploitation)}

10 
185 In order to mathematically model this step, the value of the vector $\mathrm{h}$ is reduced.

186 Variation in the vector $\stackrel{\mathbf{E}}{\mathrm{E}}$ also decreases to change the value of the vector $\mathrm{h}$, which decreases

187 from five to zero in terms of repetition.

188 The mathematical formula for the operation step is as follows:

$189 \quad \stackrel{\mathrm{m}}{\mathrm{P}}(\mathrm{x}+1)=\frac{\stackrel{\mathrm{Cu}}{\mathrm{C}}_{\mathrm{h}}}{\mathrm{N}}$

190 Where $\stackrel{\text { m }}{\mathrm{P}}(\mathrm{x}+1)$ save the best solution and updates the positions of other search agents according

191 to the position of the best search agent.

192 (iV) Search for prey (exploration)

193 A group of spotted hyenas search for prey according to their location.

194 At this stage, $\stackrel{\mathrm{B}}{\mathrm{B}}$ vector is needed to explore the prey, which provides stochastic values during the

195 iteration process. This mechanism is useful to prevent local optimization until the last iteration

196 and termination of the algorithm after compliance with the criteria. The flowchart in Figure (1)

197 shows the process of this algorithm. 


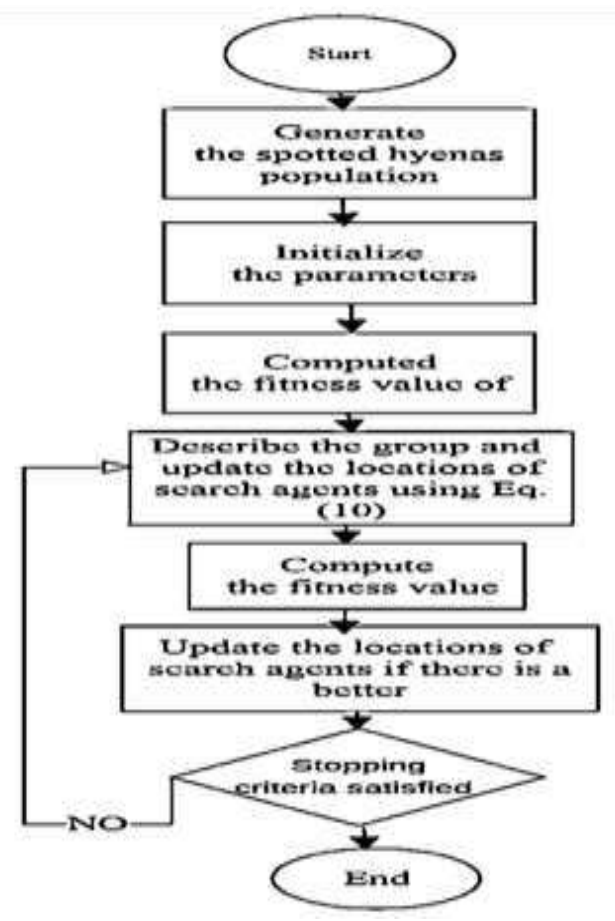

\section{4. Statistical evaluation of performance}

201 In order to compare the results of the two methods, a series of indicators or objective functions

202 must be used. These indicators are as follows (Khalifeh et al., 2020):

\section{4.1. SSQ}

204 In this paper, the target function was used to minimize the sum of squares of residuals (SSQ)

205 between observed and computed outputs according to equation (29) to estimate the optimal

206 values of parameters in the Muskingum Non-linear model.

$$
\operatorname{MinSSQ}=\sum_{t=1}^{N}\left(O_{t}-O_{c t}\right)^{2}
$$


208 Where $\mathrm{O}_{\mathrm{t}}$ is the output flow measured and $\mathrm{O}_{\mathrm{ct}}$ is the volume of calculated flood discharge routed

209 at time $\mathrm{t}$, and $\mathrm{N}$ is the number of times steps of the flood routing.

210 4.2. DPO

211 The DPO index to calculate the smallest difference between the measured peak flow and the

212 routed peak flow is as follows:

$213 \quad \mathrm{DPO}=\operatorname{minimize}\left|O_{p}-\hat{O}_{p}\right|$

214 Where DPO is the absolute value of the difference between the peak output flow measurement

215 and the routed output flow rate, $O_{p}$ is the measured peak output flow rate and $\hat{O}_{p}$ is the routed

216 output peak flow rate value.

\section{5. Data preparation}

218 Two cases were investigated in this study. The Wilson River is selected to evaluate SHO 219 Algorithm, and Kardeh River is evaluated to show performance of modified NL6 compared to $220 \quad$ NL3.

\section{5.1. The first case study _Wilson River (Smooth Single Peak Hydrograph)}

222 The example used in this study was first presented by Wilson (1974). In this example, a non-

223 linear relationship exists between the values of $\mathrm{S}_{t}$ and $\left[\mathrm{XI}_{t}+(1-\mathrm{X}) \mathrm{O}_{\mathrm{t}}\right]$, and it is possible to obtain

224 the performance of various algorithms in calculating optimal values of the Non-linear 225 Muskingum equation parameters. Furthermore, a variety of Meta-heuristic methodologies have 226 been tested in this example. The highest inflow and outflow were 111 and $85 \mathrm{~m}^{3} / \mathrm{s}$, respectively 227 (Wilson, 1974). 
228 Applying the NL3 approach to the Wilson River, the optimal values of the three model

229 parameters based on the SHO, GA and ICA algorithms were investigated as shown Table 1. The

230 SHO superiority was determined according to the results of Table 1 and Figure 2, and the routing

231 calculation was also determined according to the Wilson River data in Table 3. Table 2 shows

232 the values of the parameters obtained from the studied algorithms for the Wilson River.

233 Table 4 shows the performance of the proposed algorithms by the statistical parameters

234 including the SSQ and DPO for the Wilson River. As shown in Table 4, the SHO algorithm has a

235 better performance compared to the GA and ICA algorithms.

236 Finally, according to the results, the superiority of the SHO algorithm in Wilson flood routing

237 was determined and as a way to explain the performance of the NL6 method, the results were

238 compared with the NL3 method in Table 5.

Table 1: Values of the parameters obtained from the proposed algorithms for the Wilson River with the model (NL3)

Table 2: Values of the parameters of the algorithms used for the Wilson River

\begin{tabular}{|c|c|c|c|c|c|c|}
\hline & & & $\begin{array}{l}\text { Population size } \\
70\end{array}$ & $\begin{array}{c}\text { Iteration } \\
1000\end{array}$ & $\begin{array}{l}\text { Parameter } \\
\text { Value }\end{array}$ & SHO \\
\hline $\begin{array}{c}\text { coupling rate } \\
0.8 \\
\end{array}$ & $\begin{array}{c}\text { mutation rate } \\
0.02\end{array}$ & $\begin{array}{c}\text { Number of genes } \\
240\end{array}$ & $\begin{array}{l}\text { Population size } \\
70\end{array}$ & $\begin{array}{c}\text { Iteration } \\
1000\end{array}$ & $\begin{array}{c}\text { Parameter } \\
\text { Value }\end{array}$ & GA \\
\hline $\begin{array}{l}\text { Revolution } \\
\text { rate }\end{array}$ & $\begin{array}{l}\text { Solidarity } \\
\text { rate }\end{array}$ & Number of colonists & Population size & Iteration & Parameter & ICA \\
\hline
\end{tabular}




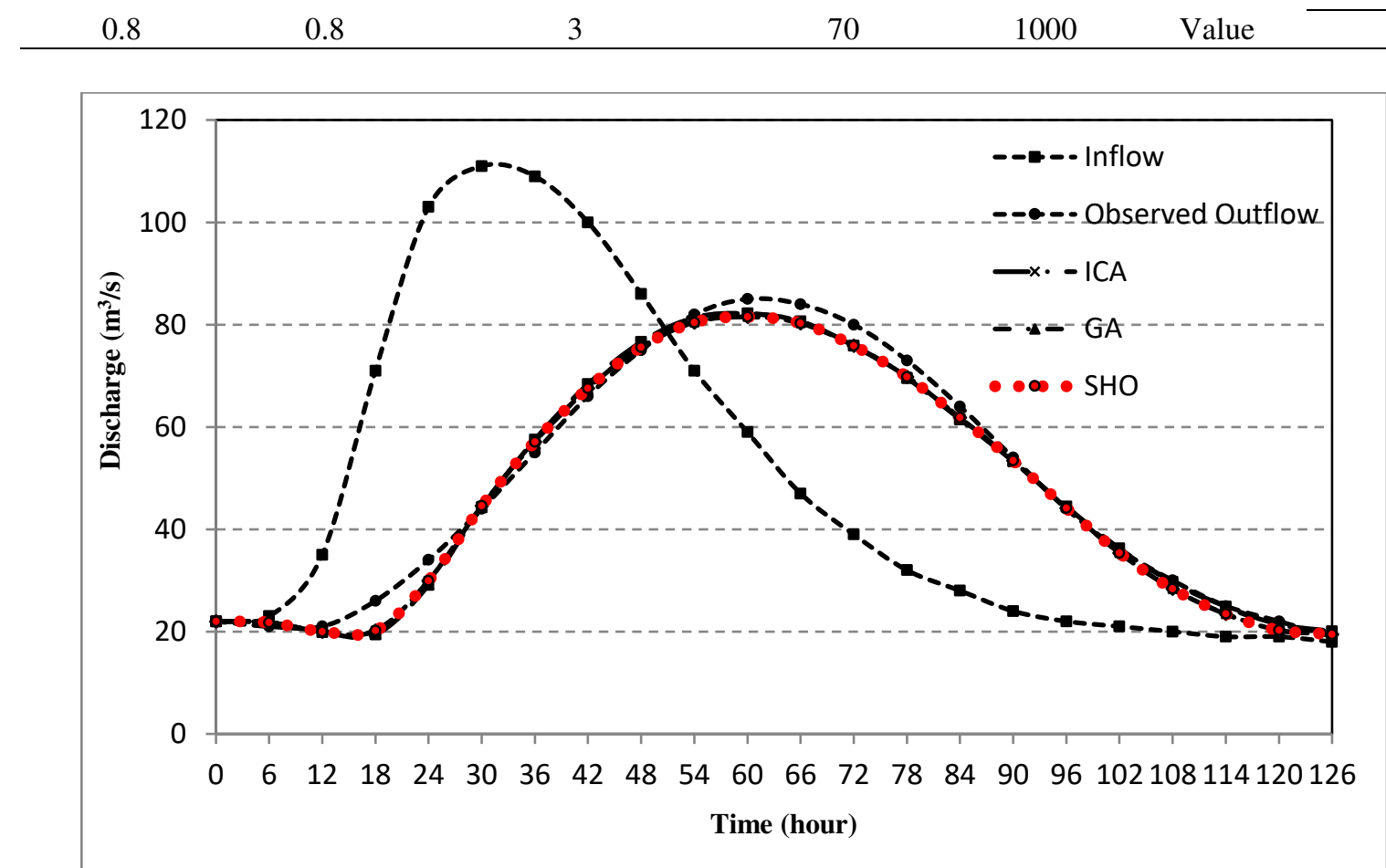

Figure 2: The output hydrograph is estimated by the algorithms investigated for the Wilson River

(NL3 model)

Table 3: Output Hydrograph Values Routed by Algorithms for Wilson River (NL3 Method)

\begin{tabular}{|c|c|c|c|c|c|}
\hline \multirow[b]{2}{*}{ ICA } & \multirow[b]{2}{*}{ GA } & \multirow[b]{2}{*}{ SHO } & \multirow{2}{*}{$\begin{array}{c}\text { Output observation } \\
\text { discharge } \\
\left(\mathbf{m}^{3} / \mathbf{s}\right)\end{array}$} & \multirow{2}{*}{$\begin{array}{r}\text { Input discharge } \\
\left(\mathrm{m}^{3} / \mathrm{s}\right)\end{array}$} & \multirow{2}{*}{ Time(hr) } \\
\hline & & & & & \\
\hline 22 & 22 & 22 & 22 & 22 & 0 \\
\hline 21.784 & 21.784 & 21.785 & 21 & 23 & 6 \\
\hline 20.00 & 19.914 & 20.014 & 21 & 35 & 12 \\
\hline 20.195 & 19.486 & 20.165 & 26 & 71 & 18 \\
\hline 29.975 & 29.155 & 29.942 & 34 & 103 & 24 \\
\hline 44.566 & 44.325 & 44.561 & 44 & 111 & 30 \\
\hline 57.104 & 57.449 & 57.113 & 55 & 109 & 36 \\
\hline
\end{tabular}




\begin{tabular}{llllll}
67.515 & 68.264 & 67.534 & 66 & 100 & 42 \\
75.576 & 76.496 & 75.598 & 75 & 86 & 48 \\
80.424 & 81.281 & 80.445 & 82 & 71 & 54 \\
81.504 & 82.125 & 81.521 & 85 & 59 & 60 \\
80.285 & 80.597 & 80.294 & 84 & 47 & 66 \\
75.871 & 75.867 & 75.871 & 80 & 39 & 72 \\
69.817 & 69.590 & 69.815 & 73 & 32 & 78 \\
61.811 & 61.524 & 61.806 & 64 & 28 & 84 \\
53.418 & 53.285 & 53.415 & 54 & 24 & 90 \\
44.140 & 44.410 & 44.146 & 44 & 22 & 96 \\
35.341 & 36.170 & 36.363 & 36 & 21 & 102 \\
28.315 & 29.589 & 28.349 & 30 & 20 & 108 \\
23.417 & 24.770 & 23.454 & 25 & 19 & 114 \\
20.239 & 21.308 & 20.264 & 22 & 19 & 120 \\
19.486 & 20.018 & 19.497 & 19 & 18 & 126 \\
\hline
\end{tabular}

252

253

Table 4: Statistical indices investigated for the Wilson River (NL3 model)

\begin{tabular}{ccc}
\hline SSQ & DPO & Algorithm \\
\hline 128.781 & 0.92 & SHO \\
138.805 & 1.5 & GA \\
130.792 & 1.09 & ICA \\
\hline
\end{tabular}

254 According to Table 5, two models of NL6 and NL3 were compared with each other based on the 255 SHO. The statistical indices of SSQ and DPO show that the optimization of the observation data 256 is better than the previous method with fewer parameters. Also measuring and calculating 257 hydrographs of the NL6 model, and comparison with the NL3 model for the first case study are 258 shown in Fig. 3. As can be seen, the calculated hydrograph is in a good agreement with the 
259 measured hydrograph. Moreover, the figure shows that the NL6 model with the accuracy of 260 discharge, calculates the peak flood hydrograph, which is an important variable in hydrograph

261 routing. Figure 4 shows the dispersion of observational and simulated data in Wilson River with

262 the coefficient of determination equal to 0.999 , which is very high accuracy.

Table 5 - Comparison of the results of the first case study

\begin{tabular}{cccccccccccc}
\hline DPO & SSQ & $\gamma$ & $C_{2}$ & $C_{1}$ & $\beta$ & $\alpha_{2}$ & $\alpha_{1}$ & $X$ & $K$ & Algorithm & Model \\
\hline 0.92 & 128.781 & ---- & ----- & ----- & 2.154 & ---- & ---- & 0.301 & 0.169 & SHO & NL3 \\
\hline 0.027 & 3.20 & 0.918 & 0.727 & 0.593 & 3.815 & 0.426 & 0.701 & 0.876 & 0.497 & SHO & NL6
\end{tabular}

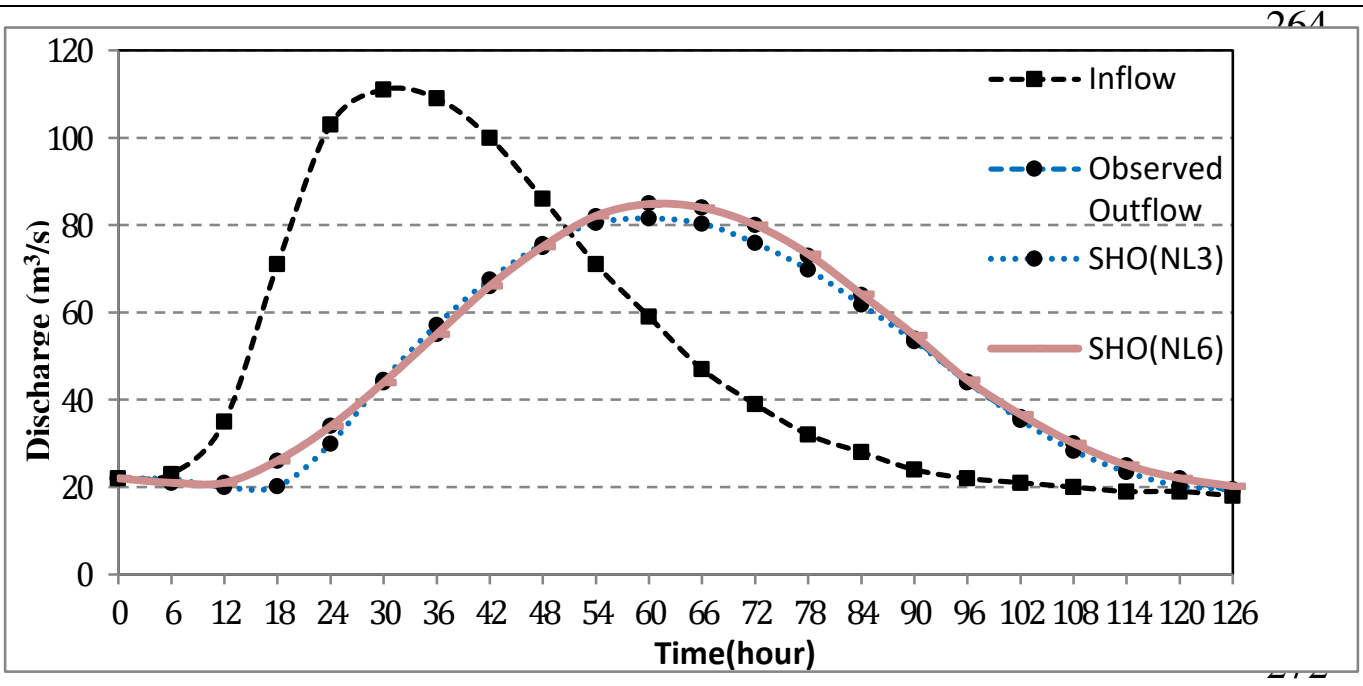




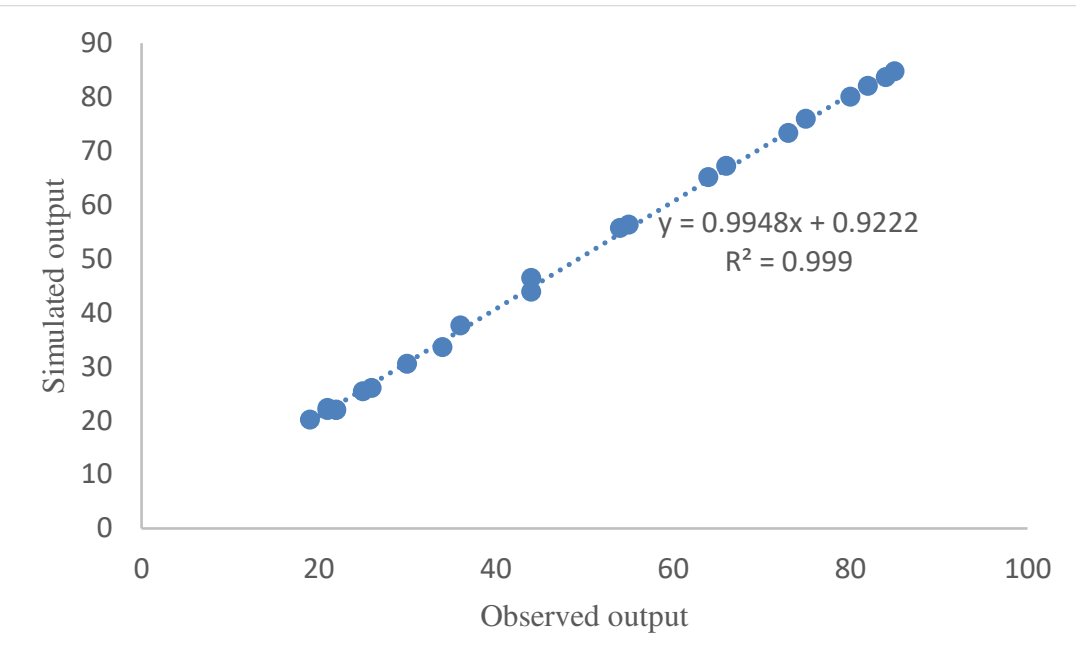

Figure 4 - dispersion of observational and routed data in Wilson River

277 5.2. The second case study- Wye River (Non-Smooth Single Peak Hydrograph)

278 The second case study is a flood that occurred on the River Wye in Britain (Nark, 1975).

279 The $69.75 \mathrm{~km}$ stretch of the Wye River from Erwood to Belmont is unbranched and has a very 280 small inflow.

281 Thus, this flood is a good test case for testing routing methods. The flood was first investigated 282 by O'Donnell et al. (1988) with a linear Muskingum model. This flood is similar to the data 283 reported by Wilson (1974) in that it shows a nonlinear relationship between flow and storage 284 volume. This case study includes $\Delta \mathrm{t}$ equal to 6 hours and $\mathrm{N}=33$.

285 According to Table 6, the comparison of the NL6 and NL3 models was performed. The values of 286 the SSQ and DPO showed that in the NL6 developed method, optimization of the data is better 287 compared to the previous method with lower parameters. In addition, the measured and 
288 computed hydrographs of the NL6 model and its comparison with the NL3 model for the second

289 case study are shown in Figure 5. It can be seen in Fig. 5 that the calculated hydrograph is in

290 good agreement with the measured hydrograph. Moreover, this figure displays that the NL6

291 model accurately calculates the discharge peak, which is an important variable in hydrograph

292 routing.

293

294

Table 6 - Comparison of the results of the second case study

\begin{tabular}{cccccccccccc}
\hline DPO & SSQ & $\gamma$ & $C_{2}$ & $C_{1}$ & $\beta$ & $\alpha_{2}$ & $\alpha_{1}$ & $X$ & $K$ & algorithm & Model \\
\hline 90.05 & 34789.39 & ----- & ----- & ----- & 1.60 & ----- & ---- & 0.416 & 0.075 & SHO & NL3 \\
\hline 72.35 & 30812.07 & 0.9505 & 0.7735 & 1.2308 & 1.399 & 1.165 & 1.055 & 0.4958 & 0.60008 & SHO & NL6 \\
\hline
\end{tabular}

295

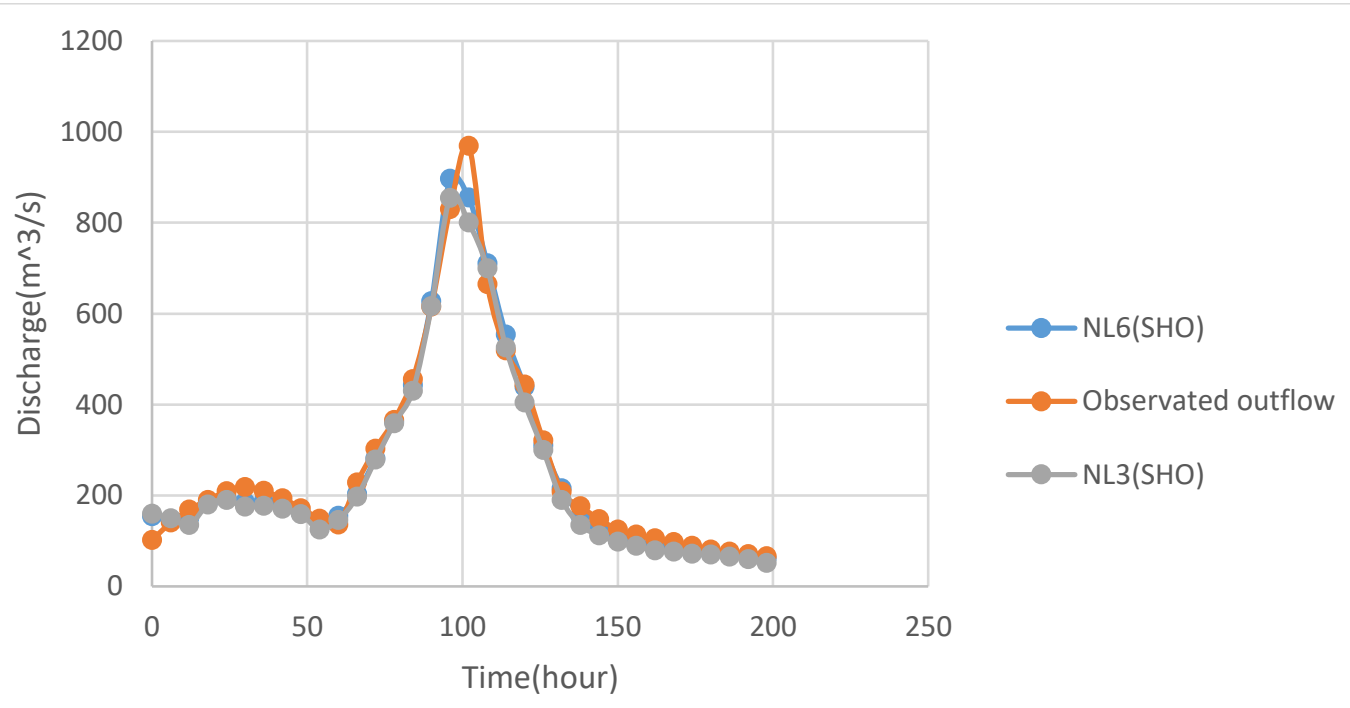




\section{Results and Discussion}

301 Due to the importance of the flood routing, and the use of linear and non-linear Muskingum

302 model for estimating the outflow hydrograph, many studies have been carried out to increase the

303 accuracy of the model. Accordingly, different relationships with different parameters related to

304 non-linear model storage are proposed.

305 Since in the previous studies, the output hydrograph error (especially at the hydrograph peak) did 306 not improve, so in this study, the 8-parameter non-linear Muskingum model NL6 was used to 307 improve the computational output hydrograph and its accuracy based on the whale optimization 308 algorithm. By applying the above approach to two case studies, containing single-dimensional 309 hydrograph and optimizing non-linear model parameters by SHO algorithm, the output 310 hydrograph results were calculated and compared with other existing models.

311 Based on the optimal values of the Muskingum non-linear model parameters and the calculated 312 output hydrographs, for both case studies, the value of all the SSQ and DPO objective functions 313 significantly decreased compared to the other existing models, and the results of output discharge

314 values are improved and brought closer to real values. The SSQ and DPO Objective functions of 315 the NL6 model for the first study is 3.20 and 0.027 , respectively, and for the second case study is 31630812.07 and 72.35 , respectively.

317 Finally, according to the results of two case studies, both models used in this paper (NL6) and 318 the proposed algorithm have performed well for estimating Non-linear parameters of the 319 Muskingum method. 
320 Accordingly, the approach of this study can be used as a good guide for flood routing in rivers

321 whose measured discharge is natural.

322 Conflict of Interest

323 The authors declare that they have no conflict of interest.

324 Data Availability Statement

325 Whole of datasets and models created or used during the paper are available from the

326 corresponding author by request.

327

328

329 References

330

- Ahmed AN, Othman FB, Afan HA, Ibrahim RK, Fai CM, Hossain MS et al., (2019). Machine learning methods for better water quality prediction. J Hydrol 578:124084.

- Chow, V. T., (1959) "Open channel hydraulics." McGraw-Hill, New York.

- Chu, H. J. and L. C. Chang., (2009). Applying particle swarm optimization to parameter estimation of the nonlinear Muskingum model. Journal of Hydrologic Engineering, 14: $1024-1027$. 
- Dhiman, G., and Kumar, V., 2017. Spotted hyena optimizer: a novel bio-inspired based metaheuristic technique for engineering applications. Advances in Engineering Software. 114(Supplement C).pp.48-70.

- Das, A., (2004) "Parameter estimation for Muskingum models". Journal of Irrigation Drainage Engineering 130(2):140-147.

- Easa SM., (2013). New and improved four parameter Non-linear muskingum model. Proceeding of the Institution of Civil Engineering-Water Management 167(5):288-298

- Farzin, S., Singh, V., Karami, H., Farahani, N., Ehteram, M., Kisi, O., . . El-Shafie, A.2018.Flood routing in river reaches using a three-parameter Muskingum model coupled with an improved bat algorithm. Water, 10.9:1130.

- Gavilan, G., Houck, M. H., (1985) "BOptimal Muskingum river routing".Proceedings of ASCE WRPMD Specialty Conference on Computer Applications in Water Resources, New York [Torno HC (ed.)], Reston, VA, USA, pp. 1294-1302.

- Geem, Z. W., (2006). Parameter estimation for the Non-linear Muskingum model using the BFGS technigue. Journal of Irrigation and Drainage Engineering, 5: 474-478. 
- Ghaleni, M., O. Bozorg Haddad and K. Ebrahimi. 2010. Optimization nonlinear Muskingum model's parameters by simulated optimization Nord algorithm. Journal of Water and Soil, 24: 908-919. (in Persian).

- Gill, M. A., (1978) "Flood routing by Muskingum method". Journal of Hydrologic 36 (3-

- Haddad, O. B., et al., (2015) "A re-parameterized and improved nonlinear Muskingum

- Khalifeh, S., Esmaili, K., Khodashenas, S., and Akbarifard, S., (2020). Data on

- Karahan, H., G. Gurarslan., A.M. ASCE and Z.W. Geem., (2013). Parameter Estimation of the Non-linear Muskingum Flood-Routing Model Using a Hybrid Harmony Search Algorithm. Journal of Hydrologic Engineering, 18: 352-360. model for flood routing." Water Resources Management 29(9):3419-3440.

- Hamedi, F., Bozorg-Haddad, O., Pazoki, M., Asgari, H. R., Parsa, M., \& Loáiciga, H. A. (2016). Parameter estimation of extended nonlinear Muskingum models with the weed optimization algorithm. Journal of Irrigation and Drainage Engineering, 142(12), 04016059. 
Algorithm. Journal of Data in Brief , Volume 30, 368 https://doi.org/10.1016/j.dib.2020.105398.

369

370

371

372

373

374

375

376

377

378

379

380

381

382

383

384

- Khalifeh, S., Esmaili, K., Khodashenas, S., and Khalifeh, V., (2020). Estimation of Nonlinear parameters of the type 5 Muskingum model using SOS Algorithm. Journal of MethodsX, Volume 7, https://doi.org/10.1016/j.mex.2020.101040.

- Khalifeh, S., Esmaili, S. A., Esmaili, K., \& Khodashenas, S., (2020). Comparison Application of the Symbiotic Organisms Search Algorithm With Meta Heuristic Algorithms in Flood Routing Model. Journal of Water and Soil, 34(2), . https://doi.org/10.22067/jsw.v34i2.85190.

- Khalifeh, S., Akbarifard, S., Khalifeh, V., and Zallaghi, E., (2020). Optimization of water distribution of network systems using the Harris Hawks optimization algorithm (Case study: Homashahr city). Journal of MethodsX, Volume 7, https://doi.org/10.1016/j.mex.2020.100948.

- Kim J. H., Z. W. Geem and E. S. Kim., (2001). Parameter estimation of the Non-linear Muskingum model using harmony search. Journal of the American Water Resources Association, 37:1131-1138.

- Mirjalili, S., \& Lewi, A., (2016). The whale optimization algorithm. Advancement Engineering Softwares, 95, 51-67. 
- McCarthy, G. T., (1938). The unit hydrograph and flood routing. Proc. Conf. of North Atlantic Division, U.S. Army Corps of Engineers, Washington, DC.

- Mohan, S., (1997). Parameter estimation of nonlinear Muskingum models using genetic algorithm. J. Hydraulic. Eng, 123: 137-142.

- O’Donnell, T., Pearson, C. P., Woods, R. A., (1988) "Improved fitting for the three parameter Muskingum procedure". Journal of Hydrologic Engineering 114(5):516-528.

- Tabari, M., Dehcheshmeh, S., (2018). Development of Nonlinear Muskingum Model Using Hybrid Evolutionary Algorithms. Journal of Iran-Water Resources Research, Volume 14(1), pp. 160-167.

- Tung, Y. K., (1985). River flood routing by nonlinear Muskingum method. Journal of Hydrologic Engineering, 111: 1447-1460.

- Wilson, E. M. (1974). Engineering hydrology, MacMillan Education, Hampshire, United Kingdom. 